\title{
LOS AVANCES EN LA IMPLANTACIÓN DE LA MEDIACIÓN COMO SISTEMA DE RESOLUCIÓN DE CONFLICTOS: ESTADOS UNIDOS, UNIÓN EUROPEA Y ESPAÑA
}

\author{
Autora: Marta Gisbert Pomatal \\ Profesora Agregada de Derecho Procesal \\ Universidad Pontificia Comillas
}

\section{Resumen}

Los sistemas de resolución de conflictos distintos al proceso judicial están creciendo significativamente como una alternativa al mismo. Antes y ahora la mediación se ha utilizado en casi todos los estados del mundo. La insatisfacción popular con la administración de Justicia que imparten los Tribunales fue creciendo a lo largo del siglo XIX. Durante los últimos cuarenta años, la mediación ha ido convirtiéndose en una clara alternativa en los ordenamientos jurídicos de los Estados Unidos y Europa. La mediación permite a los sujetos litigantes resolver disputas de forma más rápida y más barata que el proceso judicial y sin

\footnotetext{
${ }^{1}$ mgisbert@comillas.edu
} 
un deterioro importante de sus relaciones. Como resultado de estas ventajas, se utiliza la mediación en una amplia variedad de contextos y situaciones.

Palabras clave: sistemas alternativos de resolución de conflictos; mediación; Estados Unidos; Unión Europea.

The progress in the implementation of mediation as a conflict resolution system: United States, European Union and Spain

\begin{abstract}
Alternative dispute resolution is growing significantly as an alternative to judicial processes. Historically and presently mediation has been used all over the world. Popular dissatisfaction with the administration of justice was at a fever pitch by the end of the 19th century. During the last forty years, mediation has increasingly become a fixture in both the United States and European legal systems. Mediation allows disputants to resolve disputes faster and cheaper than litigation. As a result of these advantages, disputants utilize mediation in a wide variety of contexts and settings.
\end{abstract}

Key words: alternative dispute resolution; mediation; United States; European Union.

\title{
1. INTRODUCCIÓN
}

Es indiscutible que las partes entran en conflicto y nace la disputa entre ellas debido a dificultades entre las mismas desde el punto de vista comunicativo ${ }^{2}$.

Cuando la comunicación entre las partes enfrentadas no aclara a éstas la posible justificación del actuar de cada una de ellas en relación con la otra, la comprensión mutua desaparece y las próximas acciones de las partes se dirigen a buscar el enfrentamiento. Solucionar un conflicto entre los implicados depende en gran medida de la restauración de la comunicación entre ellos.

\footnotetext{
${ }^{2}$ Para una mayor profundización sobre los conflictos y la falta de comunicación puede consultarse, entre otros, Soleto, H. (Dir.), Carretero Morales, E. y Ruiz López, C. (Coor.), Mediación y resolución de conflictos: Técnicas y ámbitos, $2^{\mathrm{a}}$ ed., Tecnos, Madrid, 2013.
} 
Como dijo el historiador romano Tito Livio "es mejor y más segura una paz

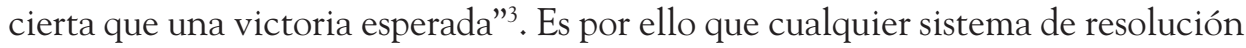
de conflictos que se enfoque desde la postura del enfrentamiento, como es un proceso judicial, va a generar una frustración a la parte que pierde que normalmente es el motivo de todo tipo de recursos y apelaciones que mantienen viva la confrontación durante mucho tiempo.

Ahora bien, se debe tener en cuenta que desde el nacimiento del Estado de Derecho, se ha entendido que el Poder Judicial, independiente y diferenciado del Poder Legislativo y Ejecutivo, es el encargado de aplicar las normas jurídicas con el fin de resolver los conflictos.

Dicho principio de independencia trae una consecuencia inevitable: los órganos jurisdiccionales deben detentar el monopolio de la Administración de Justicia, y para ello tienen como instrumento principal el proceso.

Desde principios del siglo XX, los Estados han ido asumiendo una función social y de protección de los ciudadanos. Esta concepción protectora y social del Estado ha conseguido originar en la sociedad la creencia de que sólo los órganos jurisdiccionales pueden resolver los conflictos, porque son ellos los únicos encargados de interpretar y aplicar el Derecho que tantos aspectos regula ${ }^{4}$.

Frente a esto, el proceso de mediación, en sentido amplio, significa la ayuda por parte del mediador a las partes en conflicto, para que éstas, con la menor presión externa posible, "refresquen" sus posiciones y la manera en que ven los hechos y de esta forma logren un acuerdo buscando restablecer su relación sobre la base de la fórmula ganar-ganar ${ }^{5}$.

La mediación, como alternativa a los procesos judiciales, no es concepto novedoso. La intervención de una tercera persona que ayuda a los contendientes a resolver sus conflictos y a adoptar sus propias decisiones se ha venido produciendo en diversas culturas desde tiempos lejanos. Como apunta Boqué, en todas las tradiciones culturales existe la figura de la "persona-recurso" asociada con algún miembro de la comunidad, amante de la paz que,

\section{9 a. C. -17 d. C.}

${ }^{4}$ Víd. Barona Vilar, S., Solución extrajurisdiccional de conflictos «alternative dispute resolution» (ADR) y Derecho Procesal, Tirant lo Blanch, Valencia, 1999, p. 37.

${ }^{5}$ Barona Vilar, S., "Las ADR en la justicia del siglo XXI, en especial la mediación”, Revista de Derecho Universidad Católica del Norte, (Año 18, núm. 1, 2011) pp. 185-211: "Frente a un claro fenómeno de la jurisdiccionalización de las sociedades modernas a lo largo del siglo XX, la etapa de la globalización y de la modernidad ha venido marcada por una necesidad imperiosa de buscar nuevos cauces, vías y medios que permitan ora desconflictivizar la sociedad, ora aprender a gestionar los conflictos, ora resolverlos de forma lo más pacífica y menos traumática posible. En ese contexto la evolución ha sido trascendental y en gran medida las respuestas que se ofrecen son la consecuencia inmediata de la realidad existente, tanto social, económica como políticamente establecida". 
con sentido común, interviene en las situaciones de conflicto para rebajar tensiones y llegar a acuerdos ${ }^{6}$.

Como también expone Vilalta Nicuesa, "debe decirse que el fenómeno de la mediación, de factura reciente pero de antiguas raíces, ha penetrado en los últimos años, como por capilaridad, en todos los ámbitos socioeconómicos y sectores, tanto públicos como privados. Las razones que podrían explicar el creciente interés y la implantación de la mediación son múltiples y heterogéneas y de ellas da cuenta la extensa literatura generada en los últimos años"?

Aunque el origen de la mediación, como método alternativo de resolución de conflictos, y el nacimiento del "movimiento ADR" se produjo en EE. UU., su puesta en práctica se extendió a otros países. En Europa, el primer Estado influenciado por dicho movimiento fue el Reino Unido, debido principalmente al sistema jurídico que comparten, el common law, para a continuación, expandirse al resto de países europeos cuya tradición jurídica pertenece al Derecho continental o Civil Law.

Es evidente que de manera paulatina la mediación se ha ido ocupando de la resolución de conflictos en distintas áreas sociales y humanas: interculturalidad, educación, menores, consumo, salud, asociacionismo, comunidades, etc. A partir de la pionera experiencia norteamericana, se fue reconociendo la oportunidad y viabilidad de las ADR como una función profesional de "autorregulación de disputas" sociales, alternativa o complementaria al proceso judicial. En ella jugaron un papel determinante teorías de "resolución de conflictos" como la "negociación asistida" de la Escuela de Harvard (destacamos a Fisher, Ury y Patton $)^{8}$, el "método transformativo" de Bush y Folger ${ }^{9}$, o el "círculo narrativo" de Coob, S. 1011 .

A continuación expondremos brevemente esta evolución y su influencia en la Unión Europea, con especial atención a España.

\footnotetext{
${ }^{6}$ Boqué, M. C., Guía de mediación escolar. Programa comprensivo de actividades de 6 a 16 años, edit. Octaedro, Barcelona, 2002, p.22.

${ }^{7}$ Vilalta Nicuesa, A. E., "El marco jurídico. Derecho comparado", en Casanovas, P., Magre, J., Lauroba $\mathrm{M}^{\mathrm{a}}$. E. (dir.), Materiales del Libro Blanco de la Mediación en Cataluña (Justicia i societat), vol. 2, Generalitat de Cataluña, Barcelona, 2009, p. 135.

${ }^{8}$ En Obtenga el sí. El arte de negociar sin ceder, Ediciones Gestión 2000, Barcelona, 2011.

${ }^{9}$ Bush, R. y Folger, J., La promesa de la mediación. Cómo afrontar el conflicto a través del fortalecimiento propio y el reconocimiento de los otros, Granica, Barcelona, 1996.

${ }^{10}$ Víd. Munuera Gómez, P., "El modelo circular narrativo de Sara Cobb y sus técnicas", Portularia, (vol. VII, núm. 1-2, 2007), Universidad de Huelva, pp. 85-106.

${ }^{11}$ Víd. Redorta Lorente, J. "La evolución de la mediación y el estudio del conflicto", Trabajo social hoy, (núm. 1, 2005) pp. 147-168. También Fernández Riquelme, S., "La Mediación social: itinerario histórico de la resolución de conflictos sociales", en Contribuciones a las Ciencias Sociales, enero 2010, www.eumed. net $/ \mathrm{rev} / \mathrm{cccss} / 07 / \mathrm{sfr} . h \mathrm{tm}$.
} 


\section{LA MEDIACIÓN COMO SISTEMA TRADICIONAL DE RESOLUCIÓN DE CONFLICTOS}

La doctrina coincide en que no se puede datar de forma precisa y generalizada el inicio de la mediación como alternativa a la vía judicial ${ }^{12}$.

Encontramos distintos hitos en la historia, en distintos tiempos y culturas, ejemplos referidos a varios países, grupos raciales y étnicos en los cinco continentes de aplicación de la mediación como medio de resolución alternativa de los conflictos.

Desde los tiempos bíblicos ya se auspiciaba la resolución de los conflictos por sistemas autocompositivos. En el Nuevo Testamento podemos extraer referencias a la mediación cuando el Apóstol Pablo se dirigió a la congregación de Corinto pidiéndoles que no resolvieran sus diferencias en el tribunal, sino que nombraran a personas de su propia comunidad para conciliarlas (1 Corintio 6: 1-4 ${ }^{13}$.

En muchas culturas, desde antaño las relaciones familiares y de parentesco han constituido un recurso de mediación muy importante, con la institución del jefe de familia o patriarca como figura respetada por las familias por su sabiduría y competencia para ayudar a resolver las desavenencias personales entre sus miembros. Grupos étnicos, religiosos o gremios comerciales han establecido históricamente sus propios sistemas alternativos para la resolución de desavenencias, preservando así su independencia y su paz social. De entre estas culturas podemos destacar, a modo ejemplificativo, China y Japón ${ }^{14}$.

${ }^{12}$ Víd. Macho Gómez, C., "Origen y evolución de la mediación: el nacimiento del "movimiento ADR" en Estados Unidos y su expansión a Europa", Anuario de Derecho Civil, (tomo LXVII, 2014, fasc. III, nota 1), p. 933.

${ }^{13}$ Vilalta Nicuesa, A. E., "El marco jurídico. Derecho comparado", cit. p. 129 y ss., en el que se recoge la referencia a diversos tipos de MASC a través de la historia. En el mismo sentido véase, entre otros, Weiman, G., The influential: people who influence people, State University of New York Press (SUNY), New York, 1994, pp. 9-28, donde recoge un "training manual for beginning mediators".

${ }^{14}$ Fernández Riquelme, S., "La Mediación social: itinerario histórico de la resolución de conflictos sociales", cit.: "Las sociedades orgánicas poseían, a grandes rasgos, similares mecanismos comunales y personales de Mediación en caso de conflicto entre sus miembros, propios de mentalidades sociales vinculadas a la tierra, al trabajo y a la familia (García Villaluenga, 2006, p. 170). Desde la China Imperial a la civilización grecolatina, encontramos experiencias mediadoras tradicionales, "sociedades orgánicas" bajo la ley de la tradición y la idea de jerarquía social. En el continente asiático, por ejemplo, las costumbres japonesas hacían del líder comarcal el mediador en las disputas formales; en China, se consagró como tradición milenaria, recopilada por Confucio, la resolución del conflicto a través de la persuasión moral (heredada con rasgos comunistas en los actuales Comités Populares de Conciliación). En África aún persisten amplias zonas donde rige una justicia mediadora de tintes tribales, donde la Asambleas comunales o vecinales median en los conflictos entre los miembros de una comunidad, en gran medida determinadas por los extensos círculos de parentesco. En Europa, las cofradías romanas y los gremios medievales fueron espacios laborales donde se solucionaban o encauzaban problemas propios de unas sociedades donde sus miembros eran situados por su lugar en la jerarquía en la producción, en el trabajo. En América encontramos viejos procesos de resolución autónoma y comunitaria aun vigentes: en Sudamérica subsisten tradiciones conciliadoras de origen precolombino en los mapuches chilenos o en comunidades aymaras; y en Norteamérica encontramos organismos de resolución de conflictos (agrarios, vecinales, familiares), propios de comunidades de origen europeo, como los primeros colonos evangélicos (baptistas, puritanos, cuáqueros) o como los posteriores inmigrantes judíos". 


\section{Marta Gisbert Pomata}

En la antigua China, la conciliación y la mediación fueron los principales recursos para resolver desavenencias ${ }^{15}$. La mediación se sigue ejerciendo en la República Popular China a través de los comités populares de conciliación. Desde el 1 de enero de 2011, este método alternativo para la resolución de conflictos se regula mediante la Ley de Mediación Popular que se aprobó durante el $11^{\circ}$ Congreso $\mathrm{Na}$ cional, celebrado el 28 de agosto de 2010, con el objetivo de mantener la armonía social y la estabilidad, persuadiendo a las personas enfrentadas en una controversia para que lleguen a un acuerdo basándose en tres principios: respetar el libre albedrío y la equidad de las partes, no ingerir en sus derechos ni menoscabarlos en nombre de la mediación y observar la legislación y las políticas del Estado ${ }^{16}$.

A su vez también Japón contempla la mediación ya desde sus más antiguas leyes consuetudinarias. Los samuráis, en tiempos de paz, ayudaban a resolver las disputas debido a que su código de conducta ("Bushido") les encomendaba "poner su fuerza al servicio de los más débiles y ser un sabio para los ignorantes"17.

Ahora bien, es en los Estados Unidos donde mayor desarrollo ha encontrado la mediación, antecedente directo del llamado "movimiento ADR" ( «alternative dispute resolution»), verdadero motor de la implantación de la mediación como alternativa al proceso judicial.

\section{DESARROLLO DE LA MEDIACIÓN EN ESTADOS UNIDOS}

\subsection{La mediación en el ámbito industrial}

Si bien ya existía antes ${ }^{18}$, los antecedentes y modelos de mediación más conocidos en los Estados Unidos provienen de los procedimientos de resolución de

${ }^{15}$ La Constitución de la República Popular China, de 4 de diciembre de 1982, es una de las escasas leyes fundamentales del mundo que dedica un precepto específico a la mediación; en concreto, el art. 111. Según Boqué (ya citado), la Encyclopedia of Conflict Resolution, Burgess y Burgess informan también del uso de la mediación en China, donde se remonta a más de dos mil años de antigüedad.

También Grover, K. (en "Introducción a los Programas de Mediación Comunitaria: pasado, presente y futuro" en Grover, K., Grosch, J. y Olczak, P., La mediación y sus contextos de aplicación, Paidós Ibérica, Barcelona, 1996, pp. 51-65), atribuye los orígenes de la mediación a la antigua filosofía china y añade que los chinos y otros orientales "utilizan en la actualidad la mediación como un componente importante en su sistema de justicia, tal como Confucio sugirió hace cientos de años que debía hacerse". Confucio afirmaba la existencia de una armonía natural en las relaciones humanas, que debía dejarse desenvolver (p. 54).

${ }^{16}$ Véase: http://aryme.com/actualidad-adr/747/china-promulga-ley-mediacion-popular.

${ }^{17}$ Víd. Cid Lucas, F., "Del bushi al neosamurai", Puertas de Lectura, (núm. 24, 2012), p. 112. Tan arraigada está la tradición de conciliación y mediación en la vida del japonés que se dice que en Japón hay más personas dedicadas a los arreglos florales que abogados (Folberg, J. y Taylor, A., Mediation: a comprensive to resolving conflicts without litigation, Jossey-Bass Publishers, San Francisco, 1984).

${ }^{18}$ La mediación tiene una larga historia en las colonias norteamericanas y en los Estados Unidos. La obra Justice Without Law? Resolving Disputes without lawyers, Oxford University Press, Oxford, 1984, de 
desavenencias laborales-industriales tras el Crack del 29 y la Gran Depresión de la década de 1930.

En este contexto de desigualdad social y laboral, y tras ganar las elecciones presidenciales Franklin Delano Roosevelt, el 8 de noviembre de 1932, se comienza a poner en práctica el denominado New Deal Un conjunto de medidas adoptadas con el fin de superar la tremenda crisis que asolaba EE. UU., a la vez que intentaba asegurar, según propugnaban, un auténtico bienestar a sus ciudadanos ${ }^{19}$.

También se empezaba a vislumbrar un cambio en el pensamiento jurídico, abandonando el Classical Legal Thought para comenzar a desarrollarse el Realismo Jurídico Americano ${ }^{20}$.

En ese marco se aprueba la National Labor Relations Act, el 5 julio de 1935, norma fundamental para la mediación laboral ${ }^{21}$. Con base en ella se constituyó el National Labor Relations Board, una comisión cuyo fin principal era evitar prácticas abusivas por parte de los patronos, y también supervisar las elecciones sindicales ${ }^{22}$.

La intervención de los EE. UU. en las dos guerras mundiales, y la inestable situación laboral, penitenciaria, migratoria, económica y social producida en esa década y las que le siguieron, provocaron una necesidad de buscar, primero con carácter voluntarista, particular o colectivamente, y posteriormente con intervención misma del Estado, diferentes vías de solución de los conflictos.

Durante la II Guerra Mundial, y en razón a los cambios socio-económicos que provocó, y aunque el U. S. Conciliation Service seguía funcionando, en marzo de

Auerbach, J. S., describe en su capítulo I los mecanismos alternativos de resolución de disputas utilizados por los puritanos, los cuáqueros y otras sectas religiosas, así como los grupos étnicos chinos y judíos.

${ }^{19}$ Derrotados los republicanos en las elecciones de 1932, el nuevo presidente, el demócrata F. D. Roosevelt diseñó una serie de medidas tendentes a resolver la grave depresión en que se encontraba sumida la economía norteamericana. Las disposiciones que implementó durante los primeros cien días de su mandato tuvieron continuidad a lo largo de varios años y recibieron el nombre de "New Deal". Las actuaciones se encaminaron a poner fin a los más de 12 millones de parados estadounidenses. Para ello consideró prioritario fomentar la demanda e incrementar el consumo como medios para reactivar la producción. Vid. entre otros, Schlesinger, A. M., The Crisis of the Old Order: 1919-1933 (The Age of Roosevelt, Vol. I) 1957, The Coming of the New Deal: 1933-1935 (The Age of Roosevelt, Vol. II ) 1958 y The Politics of Upheaval: 1935-1936 (The Age of Roosevelt, Vol. III) 1960.

${ }^{20}$ Vid. para una mayor profundidad de estas cuestiones, entre otros, Solar Cayón, J. I., El Realismo Jurídico de Jerome Frank. Normas, hechos y discrecionalidad en el proceso judicial, Universidad Carlos III, Madrid, 2005.

${ }^{21}$ El Tribunal Supremo, modificando su propia doctrina, entendió que la libertad contractual no era una libertad absoluta, sino que podía ser limitada a través de medidas legislativas. La modificación de la doctrina Lochner se materializó en la sentencia West Coast Hotel Company c. Parrish, 301 U. S. 1 (1937) de 29 de marzo de 1937. Para profundizar sobre dicha sentencia, vid. Beltrán de Felipe, M. y González García, J. V., Las sentencias básicas del Tribunal Supremo de los Estados Unidos, Boletín Oficial del Estado, Madrid, 2005, pp. 240-244.

${ }^{22}$ Para profundizar sobre esta Ley, víd. Arroyo Vázquez, M. L., "Un hito de la legislación laboral estadounidense: la Ley nacional de relaciones laborales o Ley Wagner", Espacio, tiempo y forma, Serie V, H. ${ }^{\text {a }}$ Contemporánea, (núm. 15, 2002), pp. 351-377. 


\section{Marta Gisbert Pomata}

1941 se creó otra agencia, la National Defense Mediation Board, cuya principal función consistía en solucionar los graves problemas laborales que existían en las industrias de defensa. Ahora bien, pronto se observó la necesidad de crear una agencia con mayor atribución de competencias ante el éxito de aceptación que tuvo este sistema. Así las cosas, en enero de 1942 se fundó, en sustitución de la National Defense Mediation Board, la segunda War Labor Board.

Esta comisión se convirtió en "una segunda instancia de apelación" en relación al U. S. Conciliation Service. Si el acuerdo logrado a través de este órgano no llegaba a satisfacer a cualquiera de las partes, éstas siempre podrían acudir a la War Labor Board.

Debemos destacar que si bien, mientras que aquél se caracterizaba por tener un conjunto de mediadores experimentados en la práctica pero con escasa formación académica, esta última estaba formada por abogados y economistas, menos familiarizados con las técnicas mediadoras, pero más acostumbrados a las actuaciones judiciales. Estas particularidades propias de los componentes de la War Labor Board, junto con su carácter de "segunda instancia", hicieron que dicha comisión, aunque estuviera autorizada para realizar mediaciones, se dedicará sobre todo a llevar a cabo arbitrajes ${ }^{23}$. Una relación que en este momento sólo se comenzaba a vislumbrar, pero que en el futuro sería construida de una forma mucho más elaborada y completamente consciente, especialmente en el comercio internacional: el med-arb.

El 23 de junio de 1947, debido a los cambios socio-económicos que se producen en estos años posteriores a la II Guerra Mundial derivados del fin de la misma, como ya mencionamos, y los que acontecen, entre otros, en el seno de las relaciones laborales (la cooperación entre los empresarios y los sindicatos también terminó, distanciándose en sus posiciones, pero con una presencia mucho más relevante que antes de los sindicatos con lo que la conflictividad laboral empeora), conlleva nuevas reformas laborales y, entre ellas, la National Labor Relations Act, fue sustituida por la Labor Management Relations Act.

La principal novedad la conforma la creación del Federal Mediation and Conciliation Service (FMCS). Esta agencia independiente sustituyó al U. S. Conciliation Service. Y debemos destacar que uno de sus preceptos establecía el deber de informar al FMCS cuando cualquiera de las partes quisiera modificar o renegociar un convenio colectivo ${ }^{24}$.

Esta agencia, con "sucursales" por todo el país, estaba formada por experimentados mediadores, forjados durante los años del New Deal y de la II Guerra

${ }^{23}$ Víd. Barret, J. T y Barret, J. P., A history of alternative dispute resolution: The story of a political, cultural and social movement, The Association For Conflict Resolution, San Francisco, 2004, p. 122.

${ }^{24}$ Víd. Moore, C. W., El proceso de mediación: Métodos prácticos para la resolución de conflictos, Granica, Buenos Aires, 1995, p. 55. 
Mundial. Por todo ello se puede decir que se logra, en estos años, la consolidación de la mediación laboral en EE. UU25.

\subsection{La mediación comunitaria y los orígenes del "movimiento ADR"}

La mediación patrocinada por los organismos oficiales no se limitó a las relaciones laborales. El Congreso de Estados Unidos sancionó la Ley de Derechos Civiles en 1964 y creó el Servicio de Relaciones Comunitarias (Community Relations Service, CRS) del Departamento de Justicia. Este organismo fue facultado para ayudar "a las comunidades y las personas a resolver las disputas, los desacuerdos o las dificultades relacionadas con las prácticas discriminatorias fundadas en la raza, el color o el origen nacional”26.

Por otro lado, en estos años sesenta se difundieron las primeras experiencias en Mediación en el ámbito de Consumo (American Arbitration Association, AAA), familiar (Association of family and Conciliation Courts, 1963), escolar (Children's Proyect for friends, 1972) y comunitaria (Community Boards de San Francisco). Estas experiencias respondían a dos fenómenos esenciales: el impacto de nuevas instituciones civiles ante la llamada "crisis de representatividad social", y el aumento de la complejidad y cantidad de los procesos judiciales ${ }^{27}$.

Por tanto, es a finales de la década de los 60 cuando la sociedad estadounidense, en general, expresa un gran interés por las formas alternativas de resolución de desavenencias. Estudiosos del derecho como L. Fuller, F. E. A. Sander, R. Fisher, todos ellos de la Harvard Law School, han contribuido notablemente a la formación del pensamiento teórico respecto a los procedimientos y aplicación de técnicas para la resolución de conflictos fuera de los tribunales ${ }^{28}$.

${ }^{25}$ La creación del FMCS es punto de referencia cuando se quiere hacer mención a la primera vez que la mediación fue utilizada en EE. UU de manera formal. Víd. para profundizar sobre esta cuestión, el trabajo citado de Macho Gómez, C., "Origen y evolución de la mediación: el nacimiento del «movimiento ADR» en Estados Unidos y su expansión a Europa”, cit.

${ }^{26}$ Título X, Ley de Derechos Civiles, 1964.

${ }^{27}$ Víd. Singer, L. R., Resolución de conflictos. Técnicas de actuación en los ámbitos empresarial, familiar y legal, Paidós, Barcelona, 1996, pp. 11-21.

${ }^{28}$ Como expone Barona Vilar, S., en su artículo cit., "La aparición de las ADR se produjo en los EE. UU. hacia la década de los años treinta del siglo pasado, como consecuencia de otro movimiento, típicamente anglosajón, denominado movimiento de libre acceso a la justicia, que pretendió asegurar que todos tuvieran la posibilidad de acceder a un medio, cualquiera que este sea, que permita efectivamente conseguir una solución al conflicto planteado. Ese movimiento de libre acceso a la justicia se dirigió a la búsqueda de alternativas a los tribunales; alternativas, muchas de ellas, en absoluto desconocidas en el sistema jurídico. Las razones que en su día facilitaron un desarrollo de estos cauces fueron varias, abarcando desde el colapso que se había venido produciendo en los órganos jurisdiccionales civiles y penales, incapaces de hacer frente a los asuntos que diariamente venían engrosando el quehacer judicial, hasta el sentimiento creciente de que faltaban mecanismos privados de resolución de las controversias, sobre todo cuando de conflictos jurídicos entre particulares se refiere, pasando por la incapacidad intrínseca del sistema de poder asegurar a todos el acceso a la justicia, a través de las plurales vías que pueden desplegarse para la obtención de la misma. Argumentos, todos ellos, que curiosamente perduran, si no es que se ven incrementados, en nuestros días". 


\section{Marta Gisbert Pomata}

Como establece Sander, aunque los orígenes del "movimiento ADR" sean complejos, la descongestión de los tribunales no es el factor más importante a la hora de explicar su nacimiento. Sino que el interés que surgió en los años sesenta por la utilización de los ADR, venía de las ventajas que éstos, y en especial la mediación, podían tener a la hora de resolver determinados conflictos ${ }^{29}$.

Por otro lado, la mediación comunitaria tuvo un gran aliado en el surgimiento, en 1964, del Law and Society Movement. Es un movimiento que pretendió describir y explicar el Derecho en términos sociales. Su máximo exponente fue L. M. Friedman ${ }^{30}$. Destacamos como una de las más importantes preocupaciones de este movimiento: el pésimo impacto del proceso judicial sobre el mantenimiento de relaciones interpersonales de larga duración.

Como expone Fernández Riquelme, el Estado de Florida fue pionero en el desarrollo de los primeros ADR: el primer Centro de Resolución de Conflictos entre ciudadanos (Condado de Dade, 1975), el primer Programa de Mediación (Condado de Broward, 1976), y el primer Centro de Resolución de Conflictos estatal (1988). Estos primeros pasos culminaron con la determinación de la Mediación como "método alternativo de administración y resolución de conflictos" con la aprobación de la Dispute Resolution Act (1980) y su sanción como paso previo a las acciones judiciales en el Código de Familia (Mandatory Mediation Act, 1981). Posteriormente se desarrollaron sistemas de mediación comunitaria con los "Centros de justicia vecinal", o la unificación de la legislación sobre Mediación con la Uniform Mediation Act (2001), así como el fomento de la profesión mediadora con la Society of professionals in dispute resolutions (SPIDR) ${ }^{31}$.

En toda esta evolución también había iniciativas privadas de ámbito nacional, estatal o local, por ejemplo, la Ford Fundation, que, entre otras iniciativas, creó en 1968 el National Center for Dispute Settlement, (NCDS) ${ }^{32}$. Hoy en día sigue funcionando ${ }^{33}$.

Podemos decir, de lo que llevamos expuesto que la aceptación de la mediación entre la población ya era un hecho. Como expone Macho Gómez ${ }^{34}$, aunque el éxito de la mediación comunitaria, en un principio, sólo fue percibido por aquellos más cercanos a los conflictos raciales y vecinales -como los trabajadores

${ }^{29}$ En "Family mediation: Problems and prospects", Mediation Quarterly (vol. 2, Diciembre 1983), pp. 3-5.

${ }^{30}$ Víd. su artículo "The Law and Society Movement”, Stanford Law Review (vol. 38, núm. 3, febrero 1986), pp. 763-780.

${ }^{31}$ Víd. Fernández Riquelme, S., "La Mediación social: itinerario histórico de la resolución de conflictos sociales", en Contribuciones a las Ciencias Sociales, cit.

${ }^{32}$ Víd. Barrett, J. T. y Barrett, J. P., A history of alternative..., cit., p. 152.

${ }^{33}$ Véase http://www.ncdsusa.org.

${ }^{34}$ En "Origen y evolución de la mediación: el nacimiento del «movimiento ADR» en Estados Unidos y su expansión a Europa", cit., p. 949. 
sociales-, años después comenzó a ser advertido también por los órganos jurisdiccionales y los abogados.

Es más, no puede dejar de mencionarse que parte del éxito actual de las mismas se justifica por toda una corriente filosófica-jurídica que otorgó relevancia a los mecanismos voluntarios de resolución de controversias que incentivan la responsabilidad y creatividad de las partes. Fue la Universidad de Harvard, a través de su corriente Critical Legal Studies o Teoría Crítica del Derecho ${ }^{35}$, quien impulsó estas teorías, que en principio tuvieron naturaleza alternativa, después pasaron a adquirir también esencia complementaria a las vías legales para integrarse finalmente, incluso, como alternativa, dentro de los procedimientos judiciales. Esta integración se produjo en la legislación estadounidense a partir de los años ochenta del siglo pasado, mientras que hubo que esperar más de veinte años para que una tendencia legislativa similar se iniciara en la Unión Europea ${ }^{36}$.

\subsection{La mediación como alternativa formal a los tribunales y el "movimiento ADR"}

En este contexto, los motivos que llevaron a producir la extensión de la mediación comunitaria al ámbito judicial fueron: la expansión de la mediación a materias como la familiar, donde conflictos como el divorcio siempre se habían llevado ante los tribunales, y de forma paralela, el continuo crecimiento de de-

${ }^{35}$ El nacimiento de los Critical Legal Studies se fija en 1977, con la celebración de la Conference on Critical Legal Studies. Esta reunión estaba principalmente formada por dos grupos, aquellos sociólogos del Derecho más progresistas, provenientes del Law and Society Movement, destacando entre ellos D. Trubek, y aquellos jóvenes profesores de Derecho, principalmente de Harvard y liderados por D. Kennedy, disconformes con el sistema establecido y defendido desde las Facultades de Derecho del país. Se trataba de una corriente filosófico-jurídica de pensamiento que mantiene una posición ideológica tendente hacia el realismo jurídico y fundamentalmente, es una respuesta negativa frente a todo tipo de normativismo. Véase para profundizar sobre este tema Pérez Lledó, J. A., El movimiento Critical Legal Studies, Tecnos, Madrid, 1996, pp. 51-68.

${ }^{36}$ Como expone Barona Vilar en "La incorporación de la Mediación en el nuevo modelo de Justicia”", en Blasco Gascó, F. de P., Clemente Meoro, M. E., Orduña Moreno, F. J., Prats Albentosa, L. y Verdera Server, R., (Coord.), Estudios jurídicos en homenaje a Vicente L. Montés Penadés, Tirant lo Blanch, Valencia, 2011, pp. 227-250: "Debe destacarse que es en el modelo anglosajón en el que germinó y posteriormente cuajó el movimiento de búsqueda de las ADRs, fruto en gran medida de posición filosófico-jurídica de pensamiento, mantenida desde los años treinta del Siglo XX, basada en el realismo jurídico. Con origen en la misma, en la década de los años setenta surge en la Universidad de Harvard una corriente de pensamiento que se vino denominando como Critical Legal Studies. Ese movimiento harvardiano va a ser el germen de numerosas actuaciones de quienes intentan luchar contra el sistema jurídico existente, básicamente en los países anglosajones, y fundamentalmente es una respuesta negativa frente a todo tipo de normativismo.

La aparición de las ADRs en los EEUU viene aparejada a otro movimiento, típicamente anglosajón, que viene denominándose como movimiento de libre acceso a la justicia, que pretende que todos tengan la posibilidad de acceder a un medio, cualquiera que éste sea, en virtud del cual se consiga efectivamente una solución a la controversia o conflicto planteado". 
mandas ante los tribunales, que provocó la celebración de The Pound Conference: Perspectives on justice in the future, o Conferencia Pound, en 1976, y por ende, el nacimiento del "movimiento ADR" 3738 .

La finalidad de esta reunión era examinar, discutir y proponer soluciones a las ineficiencias del sistema judicial estadounidense. Pues bien, una de las medidas planteadas fue la instauración de los ADR en relación con el proceso judicial, o lo que es lo mismo, la implantación de los denominados court-annexed ADR o court-connected $A D R^{39}$. Esta propuesta, que fue emitida por el profesor SANDER de la Escuela de Derecho de Harvard, no sólo consistía en una mera inclusión de los ADR en el ámbito de los tribunales, sino que fue más allá, a través de la exposición del célebre sistema denominado multi-door courthouse $e^{40}$.

El Profesor Sander, articuló esta teoría en abril de 1976 en la conferencia convocada por el Presidente del Tribunal Supremo, Warren Burger, para hacer frente a los problemas a los que se enfrentaban los jueces en la administración de justicia. El Profesor Sander planteo la organización de un sistema judicial que facilitase el ingreso a los usuarios a través de "múltiples puertas". Imagina un sistema judicial que funcione como un centro de diagnóstico para las partes, para dirigirlos al proceso de resolución de conflictos (mediación, negociación, litigios, arbitrajes, o alguna combinación de éstos) que mejor se adapte a sus propias disputas $^{41}$.

${ }^{37}$ La segunda semana de abril de 1976, bajo los auspicios de la "American Bar Association", la "Judicial Conference of the United States" (presidida por el titular de la Suprema Corte de Justicia, Warren Burger) y la "Conference of State Chief Justices", se reunió la Conferencia denominada "National Conference on the Causes of Popular Dissatisfaction with the Administration of Justice", más conocida como "Pound Conference". Fue convocada por el juez Burger, llevada a cabo en St. Paul, Minnesota, donde el fundador del sociologismo jurídico, Roscoe Pound, lanzó en 1906, la proclama inicial del movimiento de reforma procesal: "Causas de la Insatisfacción con la administración de justicia", dedicada única y exclusivamente a encontrar nuevos caminos para la solución de disputas. Académicos, miembros del Poder Judicial y juristas se entregaron a la consecución de este fin.

${ }^{38}$ Llamamos la atención sobre el hecho de que la corriente Critical Legal Studies y este movimientos nacen prácticamente a la vez, el «movimiento ADR» en 1976, y los Critical Legal Studies en 1977. Si bien, había un gran distanciamiento entre los planteamientos de una y otra, ya que la primera no aceptaba la transformación que estaba sufriendo la mediación, porque había pasado de tener una naturaleza eminentemente informal y alternativa, a estar completamente incorporada al sistema judicial. Víd. Abel, R, "The Contradictions of Informal Justice», en The politics of informal justice, (vol. I, 1982), pp. 267-320.

${ }^{39}$ Se trata de la llamada mediación intrajudicial (Víd. Blanco Carrasco, M., Mediación y sistemas alternativos de resolución de conflictos una visión jurídica, Reus, Madrid, 2009, pp. 143 y 144).

${ }^{40}$ Como nos cuenta Macho Gómez en su obra citada, "Curiosamente, en la exposición original de Sander, durante la celebración de la Conferencia Pound, éste nunca hablo de multi-door courthouse, sino que utilizó otro término, comprehensive justice center. La primera de las denominaciones, y desde luego la más famosa, surgió después, a raíz de una publicación que realizó la American Bar Association, sobre el propio discurso de Sander" referenciado en la nota 41.

${ }^{41}$ Véase, la conferencia que pronunció Sander, Varieties of dispute processing, Edited by A. Leo Levin and Russell R. Wheeler, West Pub. Co., St. Paul, Minnesota, 1979, pp. 65-87. 
Sander ofreció un enfoque absolutamente novedoso a fin de reducir la demanda del usuario sobre los tribunales de justicia ya que consideraba injustificado desaprovechar el tiempo y el talento de los jueces, quienes debían resolver cuestiones sin complejidad jurídica, en vez de dedicarse a los asuntos de mayor dificultad.

Empieza su presentación citando al profesor John Barton quien en 1975 dijo que si los casos de apelaciones continuaran creciendo en los próximos 40 años como lo vienen haciendo en la última década, en 2010 se tendrían más de 1 millón de apelaciones federales cada año, requiriendo 5000 jueces federales de apelaciones ${ }^{42}$. Para evitar la anterior predicción, Sander sugiere que se deberían explorar formas alternativas de resolver las disputas fuera de los juzgados. De acuerdo con lo anterior, la justificación de incluir diferentes métodos de resolución de conflictos en un centro de resolución de disputas es porque el sistema judicial no estaría capacitado de atender y resolver los conflictos eficientemente. De esta manera, la conciliación no tiene como característica natural el ser alternativa al proceso judicial, sino que se retoma como un mecanismo de resolución de conflictos para ser incluido en un centro junto al proceso judicial, el arbitraje, etc ${ }^{43}$.

Describió también lo que para él deberían ser los tribunales hacia el año 2000 señalando que para tal fecha no debían ser solo un juzgado sino más bien un "Centro de Resolución de Disputas". En este centro el solicitante sería canalizado a través de un funcionario encargado de analizar el caso y redirigido hacia el proceso o secuencias más apropiada de acuerdo a su naturaleza ${ }^{44}$.

Sander entendía fundamental el análisis de cinco extremos: a) la naturaleza de las disputas, teniendo en cuenta que normalmente todas ellas siempre son muy complejas; b) la relación entre los propios litigantes, porque sin duda, cuando el vínculo entre las partes es necesariamente duradero, el tratamiento del conflicto también debe ser distinto, no es cuestión de ganar o perder, tal y como ocurre en los tradicionales procesos judiciales; c) el montante del litigio, porque si son reclamaciones de pequeña cantidad, no se debiera poner en acción todos los recursos humanos y materiales que implica un proceso ante los tribunales; d) el coste, que implica el proceso y el ADR, y por último; e) la rapidez de los ADR respecto del proceso judicial, circunstancia que inevitablemente interesa, y mucho, en determinados ámbitos, sobre todo en los comerciales ${ }^{45}$.

Contra todo pronóstico, como expone Macho Gómez ${ }^{46}$ las ideas expuestas en la Conferencia Pound por Sander comenzaron a materializarse. Se creó una oficina es-

${ }^{42}$ P. 65 de la publicación citada de su conferencia.

${ }^{43}$ Pp. 66-67 de la publicación citada de su conferencia.

${ }^{44}$ P. 84 de su conferencia citada.

${ }^{45}$ Para un conocimiento más extenso de estos extremos véase la Conferencia citada pp. 72-79.

${ }^{46}$ En "Origen y evolución de la mediación: el nacimiento del «movimiento ADR» en Estados Unidos y su expansión a Europa”, cit., p. 953. 


\section{Marta Gisbert Pomata}

pecial en el Departamento de Justicia denominada The Office for Improvements in the Administration of Justice, con el fin de impulsar y analizar el avance en la aplicación de aquellos planteamientos expuestos en la citada reunión y también, tras un cuidadoso estudio de la idea del denominado multi-door courthouse. La American Bar Association se encargó de proyectar su implementación en diversos lugares del país mediante la creación de un Comité Especial de Resolución de Disputas. En 1984, este comité seleccionó tres localidades para implementar experiencias piloto: Tulsa, Oklahoma; Houston, Texas; y Washington D. C., las cuales comenzaron en su mayoría a funcionar en ese mismo año (salvo Washington D. C. que se inició en enero de 1985). Más allá de estos tres primeros proyectos piloto, otros Estados incorporaron este mecanismo ${ }^{47}$.

El Multi-door courthouse del Distrito de Columbia se instaló en la Corte Superior del distrito como una parte integrante del sistema judicial con la creación de la Multi-Door Dispute Resolution Division. El objetivo de este mecanismo es distribuir los conflictos llegados a la Corte Superior de Distrito de acuerdo a las diversas alternativas disponibles así como asistir a las partes a que puedan llegar a acuerdos que se ajusten a sus intereses, preservar relaciones y ahorrar dinero y tiempo ${ }^{48}$.

El ingreso de causas se hace por un proceso de análisis que identifica diversos modos en que pueden llegar a ser resueltas las disputas. La Mesa de Entradas o de admisión ("intake") de un multi-door courthouse tiene especialistas cuya tarea consiste en determinar cuál es el mecanismo más adecuado.

Tras el nacimiento del «movimiento ADR», la década de los años ochenta se caracterizó por el aumento de nuevas asociaciones que practicaban y promovían todo tipo de ADR, por la instauración de los primeros programas de formación en las Universidades, así como por la consolidación de estos mecanismos de resolución de conflictos en aquellos campos de actuación en los que se había experimentado durante las décadas anteriores. Como consecuencia de todos estos progresos, se generó el contexto ideal para el siguiente paso en la evolución de la implantación de las ADR, esto es, la formalización de la mediación a principios de los años noventa.

Se aprobaron, durante el año 1990, dos leyes federales que preveían su utilización: la Administrative Dispute Resolution Act, de 15 de noviembre, en adelante $\mathrm{ADRA}^{49}$, y la Civil Justice Reform Act, de 1 de diciembre, en adelante CJRA ${ }^{50}$.

${ }^{47}$ Víd. Ray, L. y Clare, A. L., "The Multi-Door Courthouse Idea: Building the Courthouse of the Future... Today", Ohio State Journal on Dispute Resolution, (v.1, núm. 1, 1985), pp. 7-54. Los objetivos de la experiencia eran los de proveer fácil acceso a la justicia, establecer redes que reducirían o eliminarían la frustración del ciudadano, y desarrollar y mejorar programas para llenar las brechas en el servicio, a fin de tornar disponibles más puertas por las cuales las disputas podrían resolverse.

${ }^{48}$ Kessler, G. y Finkelstein, L. J., "The Evolution of a Multi-door Courthouse", Catholic University Law Review, (núm. 37, 1987-1988), p. 580.

${ }^{49}$ Pub. Law 104-320 (que modifica Law 101-552 y Law 102-354). Se puede consultar en http://www. adr.gov/pdf/adra.pdf.

${ }^{50}$ Public Law 101-650. Se puede consultar en https://www.gpo.gov/fdsys/pkg/STATUTE-104/pdf/ STATUTE-104-Pg5089.pdf. 
La ADRA facultó a las agencias gubernamentales a utilizar los ADR en la mayor parte de las disputas administrativas. Y la CJRA estableció que los Tribunales Federales de Distrito comenzaran a implementar programas de resolución alternativa de disputas, para así reducir el coste y el retraso que existía, sobre todo, en las causas civiles. Posteriormente esta Ley se completó con la promulgación de otra: la Alternative Dispute Resolution Act, de 30 de octubre de $1998^{51}$ que exigía a las partes litigantes que, al menos, consideraran la posibilidad de utilizar algún tipo de resolución alternativa de disputas, al igual que también se obligaba al Tribunal a ofrecer alguno de los ADR contenidos en el programa.

Ahora bien, no se contenía ninguna norma relativa al procedimiento a seguir para aplicar los programas de ADR por parte de los tribunales, dejando plena discrecionalidad a los jueces en lo referente al desarrollo de estos métodos alternativos. Y si bien, esta falta de regulación, se vio por algunos como un acto plenamente coherente, para así evitar la judicialización de procesos que por definición, eran completamente informales y flexibles, otros entendían que existían determinadas garantías que, efectivamente, debían ser reguladas, como la confidencialidad, la neutralidad, y la formación y cualificación del mediador.

Como expone Macho Gómez ${ }^{52}$, "que esta Ley no regulara dichos extremos, no significaba que no existiera ningún tipo de ordenación al respecto. En el caso de la mediación, los principios de confidencialidad y de neutralidad, eran regulados por cada Estado, aunque la normativa era dispersa y muy distinta entre sî". Por otra parte, y en lo que se refiere a los controles de calidad de los profesionales de la mediación, lo cierto es que existía un vacío legal manifiesto, si bien, este era suplido a través de las actividades, documentos e informes elaborados por las organizaciones de ADR más importantes del país. Esta situación empezó a generar problemas. Uno de los más importantes fue el nacimiento de una cierta jurisprudencia en torno al principio de la confidencialidad, la cual establecía la obligación de los mediadores de tener que testificar en aquellos juicios posteriores a las mediaciones infructuosas en las que habían participado. El surgimiento de dicha jurisprudencia, junto con la insuficiente, y a veces, incorrecta regulación de la mediación por parte de los Estados, además de la presión ejercida por los mediadores, organizados a través de sus asociaciones, llevaría en pocos años a la aprobación de la Uniform Mediation Act, en 2001, también conocida como $\mathrm{UMA}^{53}$.

La UMA, modificada en 2003, tiene como principal finalidad homogeneizar determinadas cuestiones referentes a la mediación, que han sido tratadas de muy

\footnotetext{
${ }^{51}$ Public Law 105-315. Se puede consultar en https://www.law.cornell.edu/uscode/text/28/651.

${ }^{52}$ En "Origen y evolución de la mediación: el nacimiento del «movimiento ADR» en Estados Unidos y su expansión a Europa", cit., p. 958.

${ }^{53}$ Se puede consultar en http://www.uniformlaws.org/shared/docs/mediation/uma_final_03.pdf.
} 


\section{Marta Gisbert Pomata}

distinta forma por los cincuenta Estados. Y en su Nota preliminar ya se dice que un eje central de la Ley es la de asegurar la confidencialidad del procedimiento de mediación y promueve la autonomía de las partes dejando en sus manos las cuestiones de procedimiento que se pueden establecer por acuerdo y no necesitan establecerse imperativamente por la Ley. Además, algunos disposiciones de la Ley podrán ser modificadas por acuerdo de las partes, tal como se especifica en los comentarios a la secciones. Esta puede ser entendida como una Ley de mínimos que puede ser modificada de común acuerdo.

Las partes involucradas en el proceso así como las que en ellos participan tienen que poder hacerlo con plena sinceridad con el fin de que la mediación llegue a buen término y sobre una base voluntaria. Por ello, el núcleo central de la UMA, como decíamos, radica en el hecho de que la comunicación en la mediación es y está sujeta a confidencialidad y no puede ser objeto ni de investigación ni de utilización como prueba o evidencia en cualquier otro procedimiento que no sea el mediador. En los procedimientos derivados de la mediación, una parte puede negarse a dar publicidad y tiene derecho a prevenir a terceros contra la difusión de declaraciones/comunicaciones/informaciones producidas en el marco del procedimiento de mediación (nótese no obstante que los hechos en sí no se ven afectados por esta exigencia de confidencialidad procesal). La utilización de esta información en posteriores audiencias habrá de ir acompañada de la preceptiva autorización de las partes afectadas. Las excepciones por lo tanto a la obligación de confidencialidad deberán producirse de forma expresa escrita u oral.

La UMA, respetando los intereses y voluntades de las partes, no interfiere con aquellos estableciendo requisitos o normas que habrán de respetar o cumplir los mediadores, permitiendo así que estos queden definidos por las partes. No obstante, a los mediadores se les prohíbe expresamente presentar informes, declaraciones, evaluaciones, considerandos o cualquier otra comunicación a organismos judiciales relativos al procedimiento mediador (queda excluida de esta prohibición la información relativa a los meros hechos, quienes han participado y aquellas comunicaciones que pongan en evidencia situaciones de abuso, negligencia o renuncia). La ley establece algunos mecanismos para evitar que los mediadores se vean envueltos en incompatibilidades por conflicto de intereses. Las características y cualificaciones de los mediadores deberán ser comunicadas a las partes.

\section{LA MEDIACIÓN EN LA UNIÓN EUROPEA: ESPECIAL REFEREN. CIA A ESPAÑA}

Mientras que la expansión de la mediación estadounidense y con ella del "Movimiento ADR" fue casi de forma, podemos decir, "natural" con los países de su entorno que siguen el sistema del Common Law (Canadá, Australia y Reino Uni- 
do). Por el contrario los países cuyos ordenamientos procesales siguen el sistema del Civil Law siempre han sido más reticentes a estos sistemas autocompositivos de resolución de conflictos por tener un mayor apego a lo establecido en las leyes, al formalismo y a la codificación ${ }^{54}$.

Ahora bien, el origen marcadamente anglosajón del movimiento ADR y esa evolución aceptada y asumida en el modelo americano de justicia, no han sido óbice para que las ADR hayan ido adentrándose de forma imparable y constante en otros sistemas jurídicos de la más variada naturaleza. La introducción y evolución de las mismas en otros modelos distintos del americano se ha desarrollado, empero, por otros derroteros, atendidas las diversas realidades jurídicas nacionales antes mencionadas. De este modo, por un lado, la cultura jurídica del litigio ha sido una constante en muchos países occidentales, básicamente todos los que tuvieron su origen en el derecho romano y que posteriormente pasaron a conformar el modelo continental (el sistema del Common Law); en ellos se ha potenciado esa cultura del litigio desde la ley y desde la práctica misma, amén de que las instituciones (Colegios de Abogados, Poder Judicial y Universidad) han sido las grandes transmisoras de que conflicto y resolución del conflicto equivalía a acudir a los tribunales.

Desde hace algunos años se asiste en los Estados miembros de la Unión Europea al desarrollo de estas modalidades alternativas de resolución de conflictos, a pesar de que todo el mundo esté de acuerdo en que estos sistemas son muy antiguos. Las ventajas inherentes a estas modalidades de justicia privada y la crisis de eficacia de los sistemas judiciales suscitaron un interés renovado hacia estos métodos de apaciguamiento de los conflictos más consensuales que el recurso al juez o a un árbitro. Aunque se habían producido ya tibios avances en lo distintos países ${ }^{55}$, sobre todo en contextos concretos, no es hasta que la

\footnotetext{
${ }^{54}$ Ortuño, P., en "El "libro verde sobre las modalidades alternativas de resolución de conflictos en el ámbito civil y mercantil" de 19.04.2002 de la comisión de las comunidades europeas, Revista Iuris-La Ley, (núm. 77, Noviembre 2003), pp. 42-48: "En el ámbito de la Common Welth se han desarrollado una serie de métodos más próximos y accesibles al ciudadano, que absorben una gran parte de la litigiosidad, por lo que queda reducido el ámbito de la jurisdicción a los conflictos que no es posible solucionar por otros medios. Esto explica que en el Reino Unido existan la mitad de jueces que en España para una población que casi duplica la de nuestro país".

${ }^{55}$ Anteriormente también existían figuras e intentos aislados de la mediación, pero no es hasta estas décadas cuando empezamos a ver verdaderos impulsos de ordenación de la mediación. Como expone Fernández Riquelme, S., en "La mediación social: itinerario histórico de la resolución de conflictos sociales", La razón histórica, Revista Hispanoamericana de Historia de las Ideas, (2015) (http://www.revistalarazonhistorica.com/9-15/): "El proceso de institucionalización de la Mediación específica ha sido desigual en Europa, siendo escasa una normativa global y detallada. Nos encontramos con iniciativas normativas en sectores concretos, tales como familia, menores o consumo, y con diferencias sustantivas a nivel nacional. En Francia, deudora de la experiencia canadiense (Québec), se desarrolló desde los años 80 la Mediación familiar en ámbitos privados y asociaciones familiares, germen del primer código deontológico. A partir de esta experiencia, varias Leyes institucionalizaron la Mediación familiar civil (1995), la medicación para menores y asociaciones (1996), la reparación de menores (2002), la autoridad parental en caso
} 
Unión Europea apuesta firmemente por los MACS (Métodos Alternativos de Solución de Conflictos ${ }^{56}$ ) cuando podemos hablar de verdaderos éxitos en su implantación.

En el seno de la Unión Europea, la política que impulsa el acceso a los medios alternativos de resolución de conflictos se inscribe en el marco de facilitar a los ciudadanos un espacio de libertad, seguridad y justicia, y más concretamente, el derecho de acceso a la justicia, promoviendo la resolución satisfactoria de los conflictos, por una parte, y por otra, estableciendo unas vías de resolución que impidan el colapso de la jurisdicción, garantizando el buen funcionamiento de la administración de justicia, aunque también, ya en materia penal, y desde el punto de vista de la protección a las víctimas, se impulsa la mediación como medio de reparación de los daños producidos. En este sentido, el compromiso de los Estados miembros en el Consejo Europeo de Tampere de octubre de 1999 a establecer procedimientos de sustitución extrajudicial (apartado 30 de las conclusiones) no se limita al ámbito civil, si bien a nivel internacional, los derechos de las víctimas

de conflicto (2002) y como medidas prioritarias en conflictos familiares (2004). En Inglaterra y Gales, tomando como referente el modelo norteamericano, se inició desde 1974 la Mediación familiar ligada al proceso judicial: Comité Finer sobre el estudio de la mediación en conflictos de familias monoparentales, creación del Family Conciliation Council (1982) como organismo administrativo, elaboración de un código etico (1985), o vinculación de la Mediación con la regulación del divorcio (Family Law Act, 1996).

En Alemania la Mediación familiar adquirió cierto desarrollo desde la Directiva de 1993, que establecía los estándares profesionales y éticos de la Mediación familiar (aunque solo era obligatoria la Mediación en tres Länder, entre ellos Baviera, que aprobó la primera Ley). Se recogía la obra pionera de la Comunidad laboral alemana para la Mediación familiar de la Academia evangelista de Bad Boll (1992), y se proyectaba una Ley federal, finalmente aprobada el 15 de diciembre de 1999, que establecía que solo la actuación judicial era posible si se había realizado previamente un "Schlichtung" (o mediación), hecho que favoreció el nacimiento del Bundes-Arbeitsgemeinschaft für Familien-Mediation. (García Villaluenga, L., Mediación en conflictos familiares, cit.).

Paralelamente en Italia, junto a la tradicional mediación comercial (Código de Comercio, 1882, Código civil, 1942), comenzó su andadura la Mediación familiar con la Ley n 285 de 1997, donde se recogían varias propuestas mediadoras extrajudiciales, educativas y alternativas para conflictos de menores, y se concretó con el Proyecto de Ley sobre resolución consensuada de conflictos (2000), la Ley n ${ }^{\circ} 2594$ de 2004 sobre Mediación familiar en la intervención en conflictos familiares que afectan a los menores, se estableció la profesionalidad específica del Mediador (formación universitaria), y la Ley de Custodia compartida de 2006 introdujo la figura de la Mediación en el Código Civil italiano.

En Portugal se reguló parcialmente la actividad de la Mediación mediante la Ley sobre juzgados de Paz (2001); en Holanda se aprobó en 1974 un mecanismo de Mediación familiar no imperativa en separaciones y divorcios (empleada por organizaciones privadas desde 1950 como sistema prejudicial); en Bélgica se viene practicando la Mediación familiar desde 1980, pero fue la Ley de 19 de febrero de 2001, relativa a la mediación en materia familiar en el marco del procedimiento judicial, la que definió la figura del Mediador (abogados notarios o otras personas físicas que cumpliesen los requisitos); Austria aprobó una Ley de mediación en asuntos jurídicos civiles (2004); en Noruega se sancionó la figura del Mediador familiar desde la Ley de matrimonio de 1993, que obligaba a la mediación familiar previa y obligatoria antes de iniciar todo proceso de separación y divorcio; y Suiza introdujo en la Ley de divorcio de 2000 un protocolo de Mediación ("Convenios de Mediación" voluntarios, confidenciales y participativos).

${ }^{56}$ Véase, entre otros, Soleto Muñoz, H., "La Resolución jurídica de conflictos", en Soleto Muñoz, H. (Dir.) Mediación y resolución de conflictos: técnica y ámbitos, Tecnos, Madrid, 2011, p. 35. 
ya fueron objeto de una Declaración de la ONU, el 29 de noviembre de 1985, así como de numerosas recomendaciones del Consejo de Europa ${ }^{57}$.

El primer movimiento en este sentido lo encontramos en la Recomendación n. ${ }^{\circ}$ 7/1981 del Comité de Ministros a los Estados miembros, relativa a medidas tendentes a facilitar el derecho de acceso a la justicia adoptada, del 14 de mayo de $1981^{58}$. En esta misma línea, se aprobó unos años después, la Recomendación n. ${ }^{\circ}$ 12/1986, del Comité de Ministros a los Estados miembros, relativa a medidas tendentes a prevenir y reducir la sobrecarga de trabajo de los Tribunales de Justicia. En esta ocasión no sólo mencionaban la conciliación, como hacían en la anterior Recomendación, sino que también se referían de forma expresa a la mediación y al arbitraje. Además, es importante destacar que establecía una larga lista de eventuales campos de actuación, compuesta, principalmente, por conflictos civiles y comerciales ${ }^{59}$.

Ahora bien, fue en concreto en el campo de la mediación familiar, en donde se fueron consiguiendo los primeros y más exitosos logros en la implantación de este sistema de resolución de conflictos en la Unión Europea.

La Convención Europea sobre los Derechos de los niños de 25 de enero de 1996, señalaba en su art. 13 el desarrollo de la Medición para solucionar los pro-

\footnotetext{
${ }^{57}$ Véase, Soleto Muñoz, H., "La mediación en la Unión Europea", en Mediación y solución de conflictos, con Otero Parga, M., Tecnos, Madrid, 2007, capítulo 12, p. 186. Y continúa "La Unión Europea incluye entre sus intereses fomentar el acceso a los métodos alternativos de resolución de conflictos, lo cual es patente en su normativa concreta sobre mediación y conciliación -además del arbitraje- pero sobre todo en los textos de los Tratados, como el que aprueba una Constitución para Europa. Concretamente, en el artículo III-257.4 y III-269.1 Y 2 se establece la voluntad de favorecer el reconocimiento mutuo de resoluciones extrajudiciales, y en el artículo IlI-269.2.g) de desarrollar los métodos alternativos de resolución de conflictos".

${ }^{58} \mathrm{El}$ Consejo de Europa, consciente de la complejidad, la lentitud y el excesivo coste económico del tradicional proceso judicial, alentaba a los Estados a tomar una serie de medidas para mejorar el cumplimiento del derecho de acceso a la justicia (art. $6 \mathrm{CEDH})$. Entre dichas medidas, se encontraba la de facilitar y animar a las partes en conflicto a participar en conciliaciones o en otro tipo de vías para la solución amigable de disputas, bien antes de acudir al proceso judicial, bien en cualquier momento durante su desarrollo.

${ }^{59}$ En el seno del Consejo de Europa, se ha producido una interesante continuidad en la petición de una mayor aplicación de estas soluciones alternativas, tal como resulta de las siguientes recomendaciones del Comité de Ministros dirigidas a los Estados miembros:

Recomendación R (98), de 21 de enero de 1998, sobre mediación familiar.

Recomendación $n^{\circ} \mathrm{R}$ (99), de 15 de septiembre de 1999, sobre la mediación en asuntos penales;

Recomendación $n^{\circ} \operatorname{Rec}$ (2001) 9, de 15 de septiembre de 2001sobre alternativas a los litigios entre autoridades administrativas y particulares;

Recomendación $n^{\circ} \operatorname{Rec}(2002) 10$ sobre la mediación en cuestiones civiles;

Dictamen $n^{\circ} 6$ (2004), de 20 de abril de 2005, del Consejo Consultivo de los Jueces Europeos (CCJE) dirigido al Comité de Ministros del Consejo de Europa sobre un proceso justo en un tiempo razonable y la función del juez en los litigios teniendo en cuenta los medios alternativos de resolución de disputas;

y los trabajos desarrollados en febrero de 2008 por la Comisión Europea para la Eficiencia de la Justicia (CEPEJ), CM (2008) 23.
} 


\section{Marta Gisbert Pomata}

blemas familiares en los que se encontraban implicados los niños. La Recomendación $n^{\circ} \mathrm{R}$ (98) 1, del Comité de Ministros del Consejo de Europa a los Estados Miembros sobre la Mediación Familiar, adoptada el 21 de enero de 1998 aconsejaba, o recomendaba a los estados miembros la implementación de este método alternativo de resolución de conflictos de forma colaborativa y amistosa de modo tal que se garanticen o aseguren las futuras relaciones interpersonales con miras o expresa mención a la relaciones personales entre padres e hijos.

También hacía hincapié en que "los Estados deben reconocer la autonomía de la mediación y la posibilidad de que la mediación puede tener lugar antes, durante o después de un procedimiento judicial. Los Estados deben establecer mecanismos que: a) permitan la interrupción de los procedimientos legales para mediación tenga lugar; b) asegurar de que en tal caso la autoridad judicial mantiene el poder de tomar decisiones urgentes con el fin de proteger a las partes a sus hijos, o a sus bienes; c) informar a la autoridad competente, judicial o de otro tipo si las partes continúan con la mediación y si las partes han llegado a un acuerdo"60.

Al ámbito familiar se unió el del Consumo, con las Resoluciones R 98/257 y R 2001/310 sobre órganos y soluciones extrajudiciales en la materia; del Comercio electrónico en el mercado con dos directivas: D 2003/31 (8 de junio de 2000) y Directa Marco 2002/21 (7 de marzo de 2002), así como el Libro Verde sobre la asistencia jurídica en litigios civiles: problemas para el litigante transfronterizo, de 9 de febrero de 2000; el de los servicios financieros con el Acuerdo de 7 de mayo de 2001 sobre la creación de la red FIN-NET para la solución extrajudicial de conflictos $^{61}$. Y a todo ello se unió el Informe del Consejo Europeo de Bruselas-Laeken (diciembre de 2001) sobre la importancia de prevenir y resolver los conflictos sociales, internos y trasnacionales, mediante mecanismos voluntarios de Mediación, y el Libro Verde sobre modalidades alternativas de solución de conflictos en el ámbito del Derecho civil y mercantil (19 de abril de 2002), al que después nos referiremos.

En el ámbito Penal, la Mediación fue promovida por la R. 99/19 sobre mediación en materia penal y por la Decisión marco (2001/220/JAI) del Consejo de la Unión Europea de 15 de marzo de 2001, relativa al estatuto de la víctima en el proceso penal; a ella se unió la Directiva europea de 22.10.2004 que resaltaba los principales aspectos de la nueva Mediación social: asegurar un mejor acceso a la justicia, establecer una relación dinámica entre la mediación y el proceso civil, promover el recurso a la Mediación, asegurar la relación con la organización de los sistemas judiciales de los Estados miembros, y evaluar el impacto de los proyectos de Mediación.

\footnotetext{
${ }^{60}$ Véase su apartado V: "Relación entre la mediación y los procedimientos ante la autoridad judicial".

${ }^{61}$ Red transfronteriza de denuncia extrajudicial sobre servicios financieros. Se puede consultar en http://www.bde.es/servicio/reclama/es-FINNET-GUIDE.pdf.
} 
Pero volviendo al ámbito familiar, es a partir de aquí cuando los poderes públicos comienzan a dar un impulso importante a la mediación familiar también en España ${ }^{62}$, especialmente con la promulgación de leyes de mediación en distintas comunidades autónomas (Cataluña, Valencia, Galicia, Canarias y Castilla la Mancha. ${ }^{63}$. Dicho impulso culminó con la Ley $15 / 2005^{64}$ que en su Exposición de Motivos señalaba que "Con el fin de reducir las consecuencias derivadas de una separación y divorcio para todos los miembros de la familia, mantener la comunicación y el diálogo, y en especial garantizar la protección del interés superior del menor, se establece la mediación como un recurso voluntario alternativo de solución de los litigios familiares por vía de mutuo acuerdo con la intervención de un medidor, imparcial y neutral” ${ }^{\prime 5}$. La inclusión de la mediación en el artículo $770.7^{\circ}$ de la Ley de Enjuiciamiento Civil, como posibilidad de que las partes suspendan el proceso para acogerse a la misma, supuso una apuesta legal por potenciar estas vías de solución. Asimismo, la disposición final tercera de la

${ }^{62}$ En España se creó el primer servicio de mediación en el año 1988, situado en San Sebastián, y denominado Servicio de Mediación a la familia en conflicto. Ya en 1990, surgieron otros cuatro: a) el Servicio de Mediación familiar de la Unión de Asociaciones Familiares en Madrid; b) el Programa de Mediación Familiar del centro Ábside y la Fundación Familia, Ocio y Naturaleza; c) el Servicio de Mediación Familiar de Barcelona; d) el Servicio de Mediación Familiar del Instituto Genus, en Barcelona. Víd. Navas Navarro, S., "La mediación familiar en el derecho autonómico", en Libro homenaje al profesor Manuel Albaladejo García, Volumen 1, editado por Universidad de Murcia, Servicio de Publicaciones, Colegio Nacional de Registradores de la Propiedad y Mercantiles de España, 2005, pp. 3501-3520: "Que estos servicios de mediación comenzaran su andadura a partir de la década de los ochenta, no fue casualidad, sino la consecuencia a la promulgación de la Ley 30/1981, de 7 de julio, de modificación de la regulación del matrimonio civil en el Código civil y procedimiento a seguir en las causas de nulidad, separación y divorcio, vid. «BOE» n. ${ }^{\circ} 172$, de 20 de julio de 1981 ”.

${ }^{63}$ Para conocer más sobre estos programas de mediación familiar intrajudicial, véase, entre otros, Luquin Bergareche, R., "Teoría y práctica de la mediación intrajudicial en España: Algunos factores de eficacia de la mediación en conflictos familiares", en Pérez-Salazar, M. C., Resano M. C. y Ríos Martín, J. C. (dirs.), "La mediación civil y penal. Un año de experiencia" en Estudios de Derecho Judicial (núm. 136, 2007), pp. 44-62; y Sáez Valcárcel, R. y Ortuño Muñoz, P. (dirs.), "Alternativas a la judicialización de los conflictos: la mediación”, en Estudios de Derecho Judicial, (núm. 111, 2006), pp. 193-647; Soleto Muñoz, H., "La mediación vinculada a los tribunales" cit., pp. 255-261; Merino Ortiz, C. y Morcillo Jiménez, J., "Regulación de la mediación familiar en España. Estado de la cuestión a la luz del Proyecto de Ley de mediación. Reflexiones sobre las posibilidades de mediar y sus límites», Revista electrónica del Departamento de Derecho de la Universidad de La Rioja, REDUR, (diciembre 2011), pp. 165-189. Alaustrey Gracia, R, "Traslación de la mediación y sus acuerdos al proceso judicial”, en Materiales del Libro Blanco de la mediación en Cataluiña, Centro de Estudios Jurídios y Fomación Especializada, Departamento de Justicia de la Generalitat de Catalunya, Barcelona 2009.

${ }^{64}$ Ley 15/2005, de 8 de julio, por la que se modifican el Código Civil y la Ley de Enjuiciamiento Civil en materia de separación y divorcio, vid. BOE núm. 163, de 9 de julio de 2005.

${ }^{65}$ En el campo de la mediación familiar intrajudicial se desarrollaron distintas experiencias en los Juzgados de Barcelona, Madrid, Cádiz, Málaga y otros con distinta duración y resultados. Víd. Ortuño, P., "La mediación en el ámbito familiar", Revista jurídica de Castilla y León, (núm. 29, enero 2013), pp. 1- 23. Todas estas experiencias piloto de mediación promovidas por juzgados de familia han recibido un enorme impulso desde GEMME (Grupo Europeo de Magistrados por la Mediación). Para más información sobre este movimiento puede consultarse http://espagne.gemme.eu/. 


\section{Marta Gisbert Pomata}

Ley 15/2005, instó al Gobierno a remitir a las Cortes un Proyecto de Ley sobre Mediación basado en los principios establecidos en las disposiciones de la Unión Europea, y, en todo caso, en los de voluntariedad, imparcialidad, neutralidad y confidencialidad y en el respeto a los servicios de mediación creados por las Comunidades Autónomas ${ }^{66}$.

Por lo que respecta a la mediación civil y mercantil, el Consejo Europeo, en su reunión en Tampere el 15 y 16 de octubre de 1999, hizo un llamamiento a los Estados miembros para que crearan procedimientos alternativos y extrajudiciales destinados a mejorar el acceso a la justicia en Europa. En el año 2000, el Consejo adoptó conclusiones sobre métodos alternativos de resolución de litigios de conformidad con el Derecho civil y mercantil declarando que el establecimiento de principios básicos en dicho ámbito era un paso esencial para permitir el desarrollo y correcto funcionamiento de los procedimientos extrajudiciales de resolución de litigios en asuntos civiles y mercantiles, a fin de simplificar y mejorar el acceso a la justicia.

El 19 de abril de 2002, la Comisión Europea presentó un Libro Verde, donde se estudiaron las modalidades alternativas de solución de conflictos en el ámbito del Derecho civil y mercantil. El Comité Económico y Social Europeo aprobó el Dictamen de 11 diciembre 2002, sobre el Libro Verde sobre las modalidades alternativas de solución de conflictos en el ámbito del derecho civil y mercantil ${ }^{67}$. El Dictamen dejaba bien claro que las ADR no constituyen un medio de sustraerse a la justicia, sino una opción libremente consentida por las partes. Ofrecen a las partes un procedimiento alternativo, a la vez que se preserva su derecho fundamental de a la tutela efectiva de los tribunales ${ }^{68}$.

Las ADR se aplican, en el sentido que les da el Libro Verde a los procedimientos de resolución extrajudicial de los conflictos a excepción del arbitraje. Designan un procedimiento de mutuo acuerdo que, a menudo por mediación de un tercero imparcial e independiente, tiene como fin el acuerdo de las partes y la solución del conflicto. Las ADR se clasifican por lo general en dos categorías. Las ADR a cargo de un juez directamente, o encomendadas por éste a terceros, son ADR en el marco de los procedimientos judiciales. En cambio, se trata de ADR convencionales cuando las partes recurren a ellas al margen de todo procedimiento judicial. Las ADR responden a varios objetivos: restablecer el diálogo

\footnotetext{
${ }^{66}$ Como exponen García Villaluenga, L. y Vázquez de Castro, E. en "La mediación civil en España: luces y sombras de un marco normativo", Política y Sociedad, (vol. 50, núm. 1, 2013) pp. 71-98, en concreto p. 76: "La inactividad o la infructífera actividad del legislador estatal no se corresponde con la progresiva actividad que ha venido desarrollando el legislador autonómico".

${ }^{67} \mathrm{COM}(2002) 196$ final, Diario Oficial n ${ }^{\circ} \mathrm{C} 085$ de 08/04/2003 p. 0008 - 0013. O también se puede consultar en http://www.icam.es/docs/ficheros/201202170001_6_3.pdf.

${ }^{68}$ El Libro Verde sólo trata de las ADR en el ámbito del derecho civil y mercantil, incluido el derecho laboral.
} 
entre las partes, mantener las relaciones económicas, participar en la calidad de la justicia y contribuir a la paz social ${ }^{69}$.

Finalmente, llegó la Directiva 2008/523 donde se armonizaron ciertos aspectos de la mediación en asuntos civiles y mercantiles transfronterizos, que debían estar incorporados al ordenamiento jurídico de los Estados miembros antes del 21 de mayo de 2011. Se plasma en un texto legal las inquietudes sobre las que se venía trabajando, puesto que con anterioridad las puesta en práctica de ADR se enmarcaba en iniciativas particulares de los Estados miembros.

La referida Directiva sienta las bases para garantizar en la Unión Europea un marco jurídico "predecible" para quienes quieran recurrir a la mediación, promoviendo así un mayor uso de la misma, si bien sólo nace con la limitada vocación de ser aplicada a conflictos transfronterizos. Sin embargo, abre la posibilidad a que los estados miembros apliquen las mismas reglas en los procedimientos de mediación de carácter nacional, lo que ha determinado que se haya tomado como modelo para la legislación interna de muchos países de la UE, entre ellos España.

El impacto de la Directiva en la institución de la mediación y en la aceptación de ésta por los Tribunales de los Estados de la Unión Europea, es de gran importancia. Buena prueba de ello es el Informe de la Comisión de Asuntos Jurídicos sobre la aplicación de dicha Directiva en los estados miembros, que finaliza con una Propuesta de Resolución por el Parlamento Europeo en la que se apuesta decididamente por incluir la mediación como uno de los accesos a la Administración de justicia ${ }^{70}$.

En España los Tribunales ya llevaban ciertos años declarando en sus sentencias la deseable utilización de la mediación como vía menos traumática para la resolución de conflictos. En este sentido, entre otras, las Sentencias del Tribunal Superior de Justicia de Cataluña núm. 29/2008, de 31 de julio, (Ref. La Ley. Rec. 1636/2008) y de 3 Marzo de 2010, (Ref. La Ley, rec. 152/2008), donde se expresa que la guardia y custodia compartida puede establecerse sin que un alto grado de conflictividad signifique que "(incluso) no deba procurarse su implantación cuando resulta beneficiosa para los menores, aunque sea imponiendo en determinados casos la mediación familiar o terapias educativas".

Incluso, yendo más allá de la mediación aplicada al ámbito de los conflictos familiares, merecen destacarse las referencias que en diversas sentencias del Tribunal Supremo (sala $1^{\mathrm{a}}$ de lo civil) se hacen a la conveniencia de intentar la mediación para la solución de las controversias planteadas ante ese tribunal: STS

${ }^{69}$ Víd. Casado Román, J., "La Mediación Civil y Mercantil en el ámbito del Derecho comunitario", Diario La Ley, (núm. 7419, Sección Tribuna, 8 Jun. 2010).

${ }^{70}$ Documento de sesión del Parlamento Europeo 2009 - 2014, A7-0275/2011, 15.7.2011. INFORME de la Comisión de Asuntos Jurídicos sobre la aplicación de la Directiva sobre la mediación en los Estados miembros, su impacto en la mediación y su aceptación por los Tribunales (2011/2026(INI)) y Propuesta de Resolución adoptado por unanimidad. 
de 19 enero de 2012 (RJ 2012 \307) sostiene que «La mediación, como modalidad alternativa de solución de conflictos, llega a soluciones menos traumáticas que la judicial que dicta sentencia interpretando y aplicando correctamente la norma jurídica, resultando un vencedor y un vencido, cuando los temas jurídicos..., tienen o pueden tener un trasfondo humano, al que sí llega el instituto de la mediación $»^{71}$.

El 2 de marzo de 2012 se aprobó el Real Decreto-Ley de mediación en asuntos civiles y mercantiles, con la pretensión de cumplir dos mandatos legislativos pendientes; por una parte, la transposición de la Directiva 2008/52/CE y, por otra, la de la disposición adicional primera de la Ley de Enjuiciamiento Civil, introducida en 2005, en la que se establecía que en el plazo de un año se desarrollaría una Ley de Mediación. Posteriormente se aprobó la Ley 5/2012, de 6 de julio, que regula la mediación en asuntos civiles y mercantiles, tanto internos como transfronterizos y el 27 de diciembre de 2013 se publicó el reglamento que desarrolla la mencionada ley ${ }^{72}$. "La mediación es ya una realidad en España. Para impulsarla definitivamente es necesario el compromiso político de nuestros gobernantes: propugnando la obligatoriedad de la sesión informativa y estableciendo mecanismos para que se garantice la prestación de un servicio de calidad." afirmaba Luis Aurelio González Martín, presidente de GEMME en España en abril de este año ${ }^{73}$.

${ }^{71} \mathrm{Y}$ en la misma Sentencia se nos recuerda como "la utilidad de la mediación ya se contemplaba para asuntos civiles y mercantiles en la Directiva 2008/52/CE (LCEur 2008, 803) del Parlamento europeo y del Consejo de 21 de mayo de 2008, en la Ley 15 de/2009, de 22 de julio (LCAT 2009, 523), de la Comunidad Autónoma de Cataluña, de mediación en el ámbito del derecho privado y en el Anteproyecto de Ley de mediación en asuntos civiles y mercantiles, elevado al Consejo de Ministros por el de Justicia, el 19 de febrero de 2010". Véase también, entre otras, las sentencias de esta Sala de 2 de julio de 2009 (RJ 2009, 6462), 3 de julio de 2009 (RJ 2009, 5491), 5 de marzo de 2010, 30 de mayo de 2010, 18 de junio de 2010 (RJ 2010, 4894). También puede consultarse De la Vega Justribó, B., "Mediación civil y mercantil: La ley 5/2012, de mediación en asuntos civiles y mercantiles y la jurisprudencia del Tribunal Supremo sobre mediación. Cuestiones de la mediación concursal", Revista Crítica de Derecho Inmobiliario, (núm. 733, 2012), p. 2980.

${ }^{72}$ Para un mayor conocimiento de la mediación en España y debido a la brevedad de este trabajo, véase, entre otros, Gisbert Pomata, M y Díez Riaza, S., El contrato de mediación y el acuerdo de mediación civil y mercantil, Civitas-Thomson Reuters, 2014. Pérez Martell, R., Mediación civil y mercantil en la administración de justicia, Tirant lo Blanch, Valencia, 2008. Sáenz Valcárcel, R. y Ortuño Muñoz, P., Alternativas a la judicialización de los conflictos: la mediación, Estudios de Derecho Judicial, 111-2006, Consejo general del Poder Judicial, Madrid, 2007. Álvarez Moreno, M. T., "La mediación en asuntos civiles y mercantiles", Revista del Poder Judicial, (núm. 77, primer trimestre 2005), pp. 243-304. Fajardo Martos, P., Estrategia y mediación: análisis de las ventajas estratégicas que para la solución de conflictos empresariales ofrecen los principios y garantías que regulan la Mediación, en Métodos alternativos de solución de conflictos: perspectiva multidisciplinar, Dykinson, Madrid, 2006.

${ }^{73}$ Véase https://mediacionesjusticia.com/ 11/04/2016. En la página web del Ministerio de Justicia se pueden consultar todos los Juzgados de España que ofrecen mediación ya sea en el ámbito civil, mercantil, penal, social y familiar y los servicios de mediación en todos esos campos: https://www.administraciondejusticia.gob.es. 
Esta norma se enmarca en el Plan de modernización de la Justicia 2009-2012 con el objetivo de impulsar la resolución extrajudicial de conflictos, potenciando fórmulas complementarias en este sentido y, en particular, tratando de establecer una ligazón entre jurisdicción y mediación. La posibilidad de que sean las propias empresas las que con ayuda del mediador puedan resolver su conflicto mediante la mediación mercantil representa la libertad y agilidad que se busca en todas las relaciones comerciales y mercantiles, a diferencia de los Juzgados y del arbitraje, ya que permite alcanzar acuerdos fuera de un costoso y largo procedimiento, pues la neutralidad del mediador ayuda a crear un clima de trabajo para que los implicados puedan diseñar un acuerdo rápido, eficaz y seguro respecto a sus disputas mercantiles.

Con la implantación de la mediación a través de esta Ley se pretende descargar de trabajo a la Administración de Justicia mediante el impulso de un cauce extraprocesal de resolución de conflictos como es la mediación o, como se dice en la Exposición de Motivos, orientada «a preservar el ejercicio de la jurisdicción». Para ello, el propósito del legislador es poner en conexión la mediación y su ejercicio en el ámbito de la jurisdicción, estableciendo un régimen general para toda mediación en asuntos civiles y mercantiles que tenga lugar en nuestro país, otorgando fuerza jurídica vinculante al resultado de la misma. De esta manera, se instrumentaliza la mediación para los fines comentados.

Es más, ya en su día, la inclusión en los planes de modernización de la justicia de la mediación, era un claro signo de que el Consejo General del Poder Judicial había optado por favorecerla e impulsarla, con la previsión específica de esta instancia pre jurisdiccional en el seno de la nueva oficina judicial ${ }^{74}$.

La Ley establece como ámbito de actuación de la mediación, la relativa a asuntos civiles o mercantiles y, debe entenderse incluida también, como así se explica en su Exposición de Motivos, la mediación familiar. La mediación en los ámbitos laboral, penal, los conflictos con las Administraciones Públicas y en materia de consumo se encuentran fuera del ámbito material de la Ley, al considerarse ámbitos excluidos del poder de disposición de las partes, y siguiendo la línea que estableció la Directiva ${ }^{75}$.

\footnotetext{
${ }^{74}$ Sobre la colaboración de los tribunales en los programas de mediación, Zamora, M. E., "Mediación, una alternativa en crecimiento", La Ley, (núm. 6170, 2005), p. 16.

${ }^{75}$ Como exponen García Villaluenga, L. y Vázquez de Castro, E. en "La mediación civil en España: luces y sombras de un marco normativo", cit., p. 75: "En realidad, no se incluye la mediación en materia de consumo, al igual que ocurría en la Directiva transpuesta, puesto que dicha mediación implica unas especificidades que requieren una regulación especial. Téngase en cuenta que la Recomendación 98/257/ CE, de 30 de marzo de 1998, relativa a los principios aplicables a los órganos responsables de la solución extrajudicial de los litigios en materia de consumo fue el primer impulso que la Unión Europea aportó a los sistemas extrajudiciales de resolución de conflictos de consumo. La Comisión elabora una nueva Recomendación de 4 de abril de 2001, relativa a los principios aplicables a los órganos extrajudiciales de resolución consensual de litigios en materia de consumo, siendo incluida, esta vez, la mediación".
} 
Además de regular la mediación privada o extrajudicial ${ }^{76}$, el legislador busca también complementar proceso judicial-mediación y establece la llamada mediación intrajudicial. Es aquella que se lleve a cabo una vez se haya iniciado un proceso a través de demanda, y en cualquier momento de su devenir, es decir, que es posible que exista mediación al principio del proceso civil, en pleno proceso e incluso en fase de ejecución de sentencia y su resultado tendrá efectos en dicho proceso. En estos casos, generalmente, la iniciativa de la mediación parte del órgano jurisdiccional o bien se utilizan los servicios del órgano jurisdiccional, si bien no será él el mediador. La "función mediadora" del Juez tiene un claro límite: «la exhortación no puede ser una coacción, ni debería suponer que se adelantara a las partes cuando aún falta buena parte de la prueba—el contenido de la sentencia"77.

Si bien dicha mediación intrajudicial o conectada con el Tribunal no se aborda de forma clara en la Ley, y únicamente se hacen referencias a la suspensión del proceso para intentarse la mediación, en la misma línea establecida en la modificación de la LEC en 2005, así como a la información a las partes, en la audiencia previa del juicio ordinario o en la vista del juicio verbal, sobre la posibilidad de acudir a mediación.

Para finalizar, como últimos avances relacionados con la mediación y los sistemas alternativos de resolución de conflictos, la Directiva de Victimas de $2012^{78}$ y la Directiva de on line ADR en materia de consumo que siguen apostando por esta nueva línea de impartición de justicia, para reforzar la confianza de los consumidores en el mercado interior. La Directiva 2013/11 ha regulado por primera vez a nivel comunitario la resolución alternativa de litigios de consumo, que se complementa con el Reglamento 524/2013, dirigido a regular la resolución on line de litigios de consumo. En España está en tramitación un Proyecto de Ley de Resolución alternativa de conflictos de consumo ${ }^{79}$.

La Ley 36/2011, reguladora de la jurisdicción social, introduce una auténtica novedad al establecer, en sus artículos 63 a 73, como norma general que toda de-

\footnotetext{
${ }^{76}$ Sobre el contrato de mediación véase Díez Riaza, S., "El contrato de mediación civil y mercantil”, en El contrato de mediación y el acuerdo de mediación civil y mercantil, con Gisbert Pomata, Civitas-Thomson Reuters, 2014.

${ }^{77}$ Banacloche Palao, J., Comentarios a la Ley de Enjuiciamiento Civil (con De la Oliva y Díez-Picazo), Civitas, Madrid, 2000, p. 723.

${ }^{78}$ Directiva 2012/29/UE del Parlamento Europeo y del Consejo de 25 de octubre de 2012 por la que se establecen normas mínimas sobre los derechos, el apoyo y la protección de las víctimas de delitos, y por la que se sustituye la Decisión marco 2001/220/JAI del Consejo.

${ }^{79}$ Se puede consultar el informe al Proyecto del CGPJ en: http://www.poderjudicial.es/cgpj/es/PoderJudicial/Consejo-General-del-Poder-Judicial/Actividad-del-CGPJ/Informes/Informe-al-Proyecto-deLey-de-Resolucion-Alternativa-de-Conflictos-de-Consumo. Y para profundizar sobre este tema puede verse, entre otros, García Montor, L., "Nuevo modelo de resolución alternativa de conflictos de consumo a la luz del anteproyecto de ley de resolución alternativa de conflictos de consumo. especial referencia a las posibilidades de supervivencia de la mediación y otros mecanismos tradicionales", en Centro de Estudios de Consumo- Universidad de Castilla-La Mancha, 1 de junio 2015, http://www.uclm.es/centro/ cesco/ o Ríos Martín, J., Mediación penal y penitenciaria, Colex, $3^{\text {a }}$ ed., Madrid, 2012.
} 
manda debe ir acompañada del certificado que acredite el intento de conciliación o mediación previa ante el servicio administrativo correspondiente, el Servicio de Mediación, Arbitraje y Conciliación (SMAC) o ante órganos que asuman estas funciones en virtud de Convenio Colectivo, si bien el artículo siguiente enumera los procesos exceptuados de dicho requisito. Esta Ley no sólo introduce de forma expresa la referencia a la mediación a propósito de la conciliación preprocesal, sino también una vez iniciado el procedimiento ${ }^{80}$.

La Ley de la Jurisdicción Contencioso-administrativa 29/1998, de 13 de julio, reguladora de la Jurisdicción Contencioso-administrativa no contempla de forma expresa la posibilidad de acudir a vías alternativas para la solución de las controversias, si bien tampoco contiene ninguna prohibición al respecto. Asimismo, esta ley recoge la posibilidad de que el control de la legalidad de las actividades administrativas se efectúe por otras vías complementarias de la judicial, para evitar la proliferación de recursos innecesarios y ofrecer fórmulas poco costosas y rápidas de resolución de los numerosos conflictos ${ }^{81}$.

\section{CONCLUSIONES}

La mediación como sistema complementario de la administración de justicia es ya una realidad. En Estados Unidos se entendió mucho antes que en Europa las ventajas tan importantes que aportaba la mediación frente al proceso judicial. La Unión Europea ha sido decisiva en el empuje a los Estados miembros por este camino, que ha llevado, entre otros, a que en España se apruebe la Ley de Mediación en Asuntos Civiles y Mercantiles, sin olvidar el trabajo realizado por profesionales del Derecho, Magistrados, Jueces, Abogados, etc. durante los últimos veinte años. Ahora bien, queda mucho trabajo por hacer para seguir concienciando a la sociedad de las ventajas de este sistema de resolución de conflictos, así como de la necesidad de que se dote de los medios necesarios para su buen funcionamiento.

\section{BIBLIOGRAFÍA}

ABEL, R, "The Contradictions of Informal Justice", en The politics of informal justice, Vol. I, New York, 1982, pp. 267-320.

\footnotetext{
${ }^{80}$ Para profundizar sobre este tema puede consultarse, entre otros, López Álvarez, M. J., "Solución de conflictos laborales individuales en clave de mediación", Estudios financieros. Revista de trabajo y seguridad social, (núm. 377-378, 2014), pp. 13-57.

${ }^{81}$ Para profundizar sobre esta cuestión puede consultarse, entre otros, Avilés Navarro, M., La mediación intrajudicial en el orden contencioso-administrativo: evolución hacia una nueva realidad, Universidad Carlos III, Madrid, 2015.
} 


\section{Marta Gisbert Pomata}

ALAUSTREY GRACIA, R., "Traslación de la mediación y sus acuerdos al proceso judicial”, en Materiales del Libro Blanco de la mediación en Catalui$\tilde{n} a$, Centro de Estudios Jurídios y Fomación Especializada, Departamento de Justicia de la Generalitat de Catalunya, Barcelona, 2009.

ÁLVAREZ MORENO, M. T., "La mediación en asuntos civiles y mercantiles", Revista del Poder Judicial, (núm. 77, primer trimestre 2005), pp. 243-304.

ARROYO VÁZQUEZ, M. L., "Un hito de la legislación laboral estadounidense: la Ley nacional de relaciones laborales o Ley Wagner", Espacio, tiempo y forma, (Serie V, H. ${ }^{a}$ Contemporánea, núm. 15, 2002), pp. 351-377.

AUERBACH, J. S., Justice Without Law? Resolving Disputes without lawyers, Oxford University Press, Oxford,1984.

AVILES NAVARRO, M., La mediación intrajudicial en el orden contenciosoadministrativo: evolución hacia una nueva realidad, Universidad Carlos III, Madrid, 2015.

BANACLOCHE PALAO, J., Comentarios a la Ley de Enjuiciamiento Civil (con De la Oliva y Díez-Picazo), Civitas, Madrid, 2000.

BARONA VILAR, S., Solución extrajurisdiccional de conflictos «alternative dispute resolution» (ADR) y Derecho Procesal, Tirant lo Blanch, Valencia, 1999.

BARONA VILAR, S., "Las ADR en la justicia del siglo XXI, en especial la mediación", Revista de Derecho Universidad Católica del Norte, (año 18, núm. 1, 2011), pp. 185-211.

BARONA VILAR, S., "La incorporación de la Mediación en el nuevo modelo de Justicia", en Blasco Gascó, F. de P., Clemente Meoro, M. E., Orduña Moreno, F. J., Prats Albentosa, L. y Verdera Server, R., (coord.), Estudios jurídicos en homenaje a Vicente L. Montés Penadés, Tirant lo Blanch, Valencia, 2011.

BARRETT, J. T. y BARRETT, J. P., A history of alternative dispute resolution: The story of a political, cultural and social movement, The Association For Conflict Resolution, San Francisco, 2004.

BELTRÁN DE FELIPE, M. y GONZÁLEZ GARCÍA, J. V., Las sentencias básicas del Tribunal Supremo de los Estados Unidos, Boletín Oficial del Estado, Madrid, 2005.

BLANCO CARRASCO, M., Mediación y sistemas alternativos de resolución de conflictos una visión jurídica, Reus, Madrid, 2009.

BOQUÉ, M. C., Guía de mediación escolar. Programa comprensivo de actividades de 6 a 16 años, Octaedro, Barcelona, 2002.

BUSH, R. y FOLGER, J., La promesa de la mediación. Cómo afrontar el conflicto a través del fortalecimiento propio y el reconocimiento de los otros, Granica, Barcelona, 1996. 
CASADO ROMÁN, J., "La Mediación Civil y Mercantil en el ámbito del Derecho comunitario", Diario La Ley, (núm. 7419, Sección Tribuna, 8 Jun. 2010).

CID LUCAS, F., "Del bushi al neosamurai", Puertas de Lectura, Universidad de Extremadura, (núm. 24, 2012).

DE LA VEGA JUSTRIBÓ, B., "Mediación civil y mercantil: La ley 5/2012, de mediación en asuntos civiles y mercantiles y la jurisprudencia del Tribunal Supremo sobre mediación. Cuestiones de la mediación concursal”, Revista crítica de Derecho Inmobiliario, (núm. 733, 2012).

KESSLER, G. y FINKELSTEIN, L. J., "The Evolution of a Multi-door Courthouse", Catholic University Law Review, (núm. 37, 1987-1988).

FAJARDO MARTOS, P., Estrategia y mediación: análisis de las ventajas estratégicas que para la solución de conflictos empresariales ofrecen los principios y garantías que regulan la Mediación, en Métodos alternativos de solución de conflictos: perspectiva multidisciplinar, Dykinson, Madrid, 2006.

FERNÁNDEZ RIQUELME, S., "La Mediación social: itinerario histórico de la resolución de conflictos sociales”, Contribuciones a las Ciencias Sociales, (enero 2010).

FERNÁNDEZ RIQUELME, S., "La mediación social: itinerario histórico de la resolución de conflictos sociales”, La razón histórica, Revista Hispanoamericana de Historia de las Ideas, (2015) http://www.revistalarazonhistorica.com/9-15/.

FOLBERG, J y TAYLOR, A., Mediation: a comprensive to resolving conflicts without litigation, Jossey-Bass Publishers, San Francisco, 1984.

GARCÍA VILLALUENGA, L. y VÁZQUEZ DE CASTRO, E.,"La mediación civil en España: luces y sombras de un marco normativo”, Política y Sociedad, (vol. 50, núm. 1, 2013) pp. 71-98.

GISBERT POMATA, M y DÍEZ RIAZA, S., "El contrato de mediación civil y mercantil", en El contrato de mediación y el acuerdo de mediación civil y mercantil, Civitas-Thomson Reuters, 2014.

GROVER, K.; GROSCH, J. y OLCZAK, P., La mediación y sus contextos de aplicación, Paidós Ibérica, Barcelona, 1996.

LÓPEZ ÁLVAREZ, M. J., "Solución de conflictos laborales individuales en clave de mediación", Estudios financieros. Revista de trabajo y seguridad social, (núm. 377-378, 2014), pp. 13-57.

LUQUIN BERGARECHE, R., "Teoría y práctica de la mediación intrajudicial en España: Algunos factores de eficacia de la mediación en conflictos familiares", en M. C. Pérez-Salazar Resano, M. C. y Ríos Martín, J. C. (dirs.), "La mediación civil y penal. Un año de experiencia”, Estudios de Derecho Judicial, (núm. 136, 2007), pp. 44-62.

MACHO GÓMEZ, C., "Origen y evolución de la mediación: el nacimiento del "movimiento ADR" en Estados Unidos y su expansión a Europa”, Anuario de Derecho Civil, (tomo LXVII, 2014, fasc. III). 


\section{Marta Gisbert Pomata}

MERINO ORTIZ, C. y MORCILLO JIMÉNEZ, J., "Regulación de la mediación familiar en España. Estado de la cuestión a la luz del Proyecto de Ley de mediación. Reflexiones sobre las posibilidades de mediar y sus límites", Revista electrónica del Departamento de Derecho de la Universidad de La Rioja, (diciembre 2011), pp. 165-189.

MOORE, C. W., El proceso de mediación: Métodos prácticos para la resolución de conflictos, Granica, Buenos Aires, 1995.

MUNUERA GÓMEZ, P., "El modelo circular narrativo de Sara Cobb y sus técnicas", Portulario (vol. VII, núm. 1-2, 2007, Universidad de Huelva), pp. 85-106.

NAVAS NAVARRO, S., "La mediación familiar en el derecho autonómico", en Libro homenaje al profesor Manuel Albaladejo García, Volumen 1, editado por Universidad de Murcia, Servicio de Publicaciones, Colegio Nacional de Registradores de la Propiedad y Mercantiles de España, 2005, pp. 3501 3520.

ORTUÑO MUÑOZ, P., "El "libro verde sobre las modalidades alternativas de resolución de conflictos en el ámbito civil y mercantil" de 19.04.2002 de la comision de las comunidades europeas", Revista IURIS-LA LEY, (núm. 77, noviembre 2003).

PÉREZ LLEDÓ, J. A., El movimiento Critical Legal Studies, Tecnos, Madrid, 1996. PÉREZ MARTELL, R., Mediación civil y mercantil en la administración de justicia, Tirant lo Blanch, Valencia, 2008.

RAY, L y CLARE, A. L., "The Multi-Door Courthouse Idea: Building the Courthouse of the Future... Today", Ohio State Journal on Dispute Resolution, (vol.1, núm.1, 1985), pp. 7-54.

REDORTA LORENTE, J., "La evolución de la mediación y el estudio del conflicto", Trabajo social hoy, (núm. 1, 2005), pp. 147-168.

RIOS MARTÍN, J., Mediación penal y penitenciaria, Colex, $3^{\text {a }}$ ed., Madrid, 2012.

SÁEZ VALCÁRCEL, R. y ORTUÑ̃ MUÑOZ, P. (dirs.), "Alternativas a la judicialización de los conflictos: la mediación”, Estudios de Derecho Judicial, (núm. 111, 2006), pp. 193-647.

SANDER, F. E. A., Varieties of dispute processing. Edited by A. Leo Levin and Russell R. Wheeler, West Pub. Co., St. Paul, Minnesota, 1979.

SANDER, F. E. A, "Family mediation: Problems and prospects", Mediation Quarterly, (vol. 2, Diciembre 1983).

SANDER, F. E. A, "The Law and Society Movement", Stanford Law Review, (vol. 38, núm. 3, febrero 1986), pp. 763-780.

SCHLESINGER, A. M., "The Crisis of the Old Order: 1919-1933" (The Age of Roosevelt, Vol. I) 1957, "The Coming of the New Deal: 1933-1935" (The Age of Roosevelt, Vol. II ) 1958 y "The Politics of Upheaval: 19351936" (The Age of Roosevelt, Vol. III) 1960. 
SINGER, L. R., Resolución de conflictos. Técnicas de actuación en los ámbitos empresarial, familiar y legal, Paidós, Barcelona, 1996.

SOLAR CAYÓN, J. L., El Realismo Jurídico de Jerome Frank. Normas, hechos y discrecionalidad en el proceso judicial, Universidad Carlos III, Madrid, 2005.

SOLETO MUÑOZ, H., "La mediación en la Unión Europea", en Mediación y solución de conflictos, con OTERO PARGA, M., Tecnos, Madrid, 2007.

SOLETO MUÑOZ, H., "La Resolución jurídica de conflictos", en Soleto Muñoz, H. (dir.) Mediación y resolución de conflictos: técnica y ámbitos, Tecnos, Madrid, 2011.

SOLETO MUÑOZ, H. (dir.) CARRETERO MORALES, E. y RUIZ LÓPEZ, C. (coord.), Mediación y resolución de conflictos: Técnicas y ámbitos, Tecnos, $2^{a}$ ed., Madrid, 2013.

VILALTA NICUESA, A. E., "El marco jurídico. Derecho comparado", en Casanovas, P., Magre, J. y Lauroba, M ${ }^{\mathrm{a}}$. E. (dir.), Materiales del Libro Blanco de la Mediación en Cataluña (Justicia i societat), vol. 2, Generalitat de Cataluña, Barcelona, 2009, Vol. 2.

WEIMAN, G., The influential: people who influence people, State University of New York Press (SUNY), New York, 1994. 